\title{
Integrated application for automatic schedule-based distribution and monitoring of irrigation by applying the waterfall model process
}

\author{
Aulia Naufal Afif ${ }^{1}$, Fiftin Noviyanto ${ }^{2}$, Sunardi $^{3}$, Son Ali Akbar ${ }^{4}$, Eko Aribowo \\ ${ }^{1,2,5}$ Dpartement of Informatics, Universitas Ahmad Dahlan Yogyakarta, Indonesia \\ ${ }^{3,4}$ Dpartement of Electrical Engineering, Universitas Ahmad Dahlan Yogyakarta, Indonesia
}

\begin{tabular}{l}
\hline \hline Article Info \\
\hline Article history: \\
Received Nov 15, 2018 \\
Revised Dec 1,2018 \\
Accepted Sep 26, 2019 \\
\hline
\end{tabular}

Keywords:

IoT

Irrigation

Mobile application

Monitoring

Waterfall development

\begin{abstract}
$40 \%$ of areas in Indonesia are still using rainwater as a source for irrigation. Type of wetland rainwater always depends on weather that is currently difficult to predict. In addition, the frequency of field cultivation became limited. Irrigation water can come from a dam or a spring in the mountains. Limited water source generates the need to manage water distribution in all areas of rice fields. For every 1 hectare fields, at least 0.5 litres of water per second is needed. The imbalance between the field and the available water discharge can cause conflicts in the Community farmers manage field. The purpose of this research is to assist in the Assembly Of Farmer Water users ("Perkumpulan Petani Pemakai Air" or "P3A") manage the scheduling and controlling irrigation sluice based IoT using mobile applications. The waterfall process model applied in developing mobile applications. Every feature that is created has been tested directly using Unit tests based on the application of the system used. The test is done by observing the system inputs and outputs of the system usability scale (SUS). Tests are also carried out using Post-Study with method of the SUS.
\end{abstract}

This is an open access article under the $\underline{C C B Y-S A}$ license.

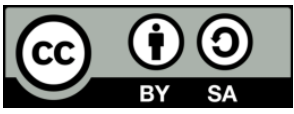

Corresponding Author:

Fiftin Noviyanto,

Department of Informatics Engineering,

Universitas Ahmad Dahlan,

Yogyakarta, Indonesia.

Email: fiftin.noviyanto@tif.uad.ac.id

\section{INTRODUCTION}

Rice fields are still a primary source to produce rice even though food technology has found a variety of rice that can be cultivated on dry land. The availability of rice, which is a major source of food in Indonesia, strongly influenced by the success of farmers in the process [1,2]. Paddy is one of those plants that require water for irrigation procees. If the water supply is not quite enough when rice cultivation then harvests will fail and food stocks will be limited which in turn will affect the price of rice in the market.

In Indonesia rules, that has the President's decision No. 31999 declared which determination of the regulatory management of irrigation is done gradually and selectively to a democratic Assembly of Farmer Water Users ("Perkumpulan Petani Pemakai Air" or "P3A") with the principle of one network irrigation or unity in management. Unfortunately, due to the human factor, there is the problem of inequa lity occur, there are farmers who have higher economic level takes precedence over farmers who have low ore economy. The limited water sources for irrigation of the field require the same water distribution to all areas of the field $[3,4]$. The imbalance between areas of irrigation and resources available can lead to conflict within the farming community. Wireless environmental sensors and automatic irrigation technology can be 
used to optimize the irrigation system [5], but requires high costs [6]. Social conflicts between farmers often occur because of conflicts in order to irrigation water. This conflict can also be caused by differences in needs among owners of water sources and farmers. The solution needed to solve the root of the problem by dividing the irrigation.

Previous research was used as a basis for reviews of technology development in smart agriculture management. Water management is vital for irrigation a ctivities in the agriculture field that capable to keep farmers society positive relationship issues [7]. So, Technology applied based on automation scheduling and monitoring in agriculture, that able to increase moral positive interactive and the capacity of yields $[8,9]$. In Addition, Technology can be implemented on the smart system for making the automation decision process in agriculture field that developed and utilized using true information through Internet connectivity [10]. The advantages of them are can reduce the crisis of conflict interest caused that monitoring in real-time condition and accessible by farmers. Moreover, the smart system should be user-friendly and intelligent processing to acquisition and prediction of precision farming resources. For example, IoT-based is most popular implemented for agriculture precision yields which is sensing implemented [10], also uses MQTT and HTTP web-based [11]. That powerful informed actual condition about the current crop, water management from a distant location [12-14]. Several studies improved the web-based system used IEEE 802.15.4 Protocol and web services (web of things) into the internet of things system [15, 16]. An application developed to control agricultural motor is very useful for farmers [17]. The application developed to regulate water distribution automation based on the distribution of mobile applications integrated scheduling. The reason to make this application on a smartphone is based on statistics, that smartphone users in Indonesia are very high, with 48\% [18]. This amount is higher than that of other ASEAN countries. Application made by the JAVA programming language with android as the platform. Although these operating systems have been launched for a long time, the system is getting its popularity only a few years ago [19]. In another case, the smart system has related by energy-consuming from integrated more component it caused pollution effect in agriculture. By developing smart energy especially in a griculture fields, that can avoided the emession generated from technology outcome [20, 21].

Based on the above issues and some earlier research, this research develops auto mation distribution and irrigation schedule based monitoring. Research conducted in some paddy fields with different areas. This research does not cover the manufacture of tools for water distribution, because it has been completed in previous studies entitled irrigation distribution automatization based on scheduling system [22].

\section{RESEARCH METHOD}

This research is applied to irrigation systems in the rice fields around the village of Wonosobo Regency. There are two methods used to develop this application, methods of analysis and design methods. the method of analysis carried out interviews, surveys, observation, a nalysis and similar applications. Design methods used in developing this application was the Waterfall Model, which consists of 5 steps [23]; Communication, Planning, modelling, construction, and placement as seen in Figure 1. This research focuses on the development of monitoring and control of the sluice-based schedule. Based on observations, there are two areas of rice fields to be used in this research. Test the water flow from both fields yield the time to fill one of the plots, which is about 6 minutes.

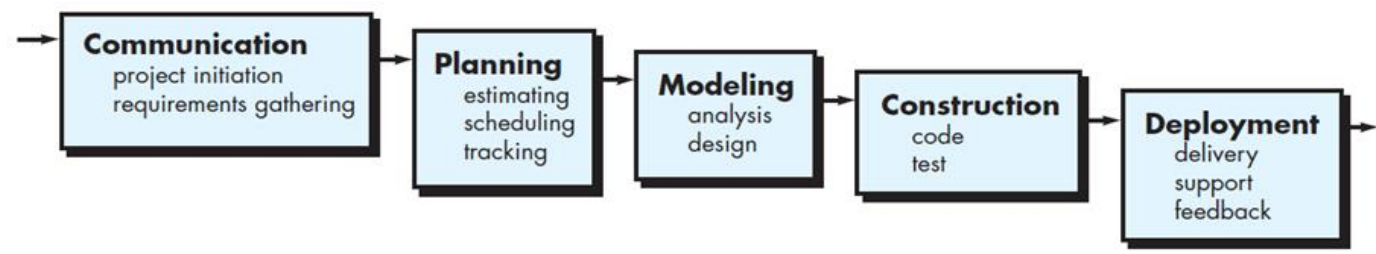

Figure 1. Waterfall model [23]

\subsection{Software requirement specification (SRS)}

SRS refers to specification requirements that are made when developing software or applications. There are 5 requirements, below is the SRS for this research:

- Application provides information on the water height of each plot which already has a sensor.

- Application provides information on soil moisture of each plot which already has a sensor.

- Application provides information via a notification when the floodgates open outside the specified schedule. 
- Application provides a menu to control the locks manually if there are indications of theft of water.

- Application provides a menu to control the schedule of opening and closing the floodgates.

\subsection{Analysis}

The application being developed is called "E-irrigation". This application is integrated with the MySQL database where the data will be converted into data to JSON (JavaScript Object Notation) so that it is readable by Android applications. Description of the business process flow analysis the use of E-control feature, particularly irrigation scheduling floodgates, is the irriga tion water as shown in Figure 2.

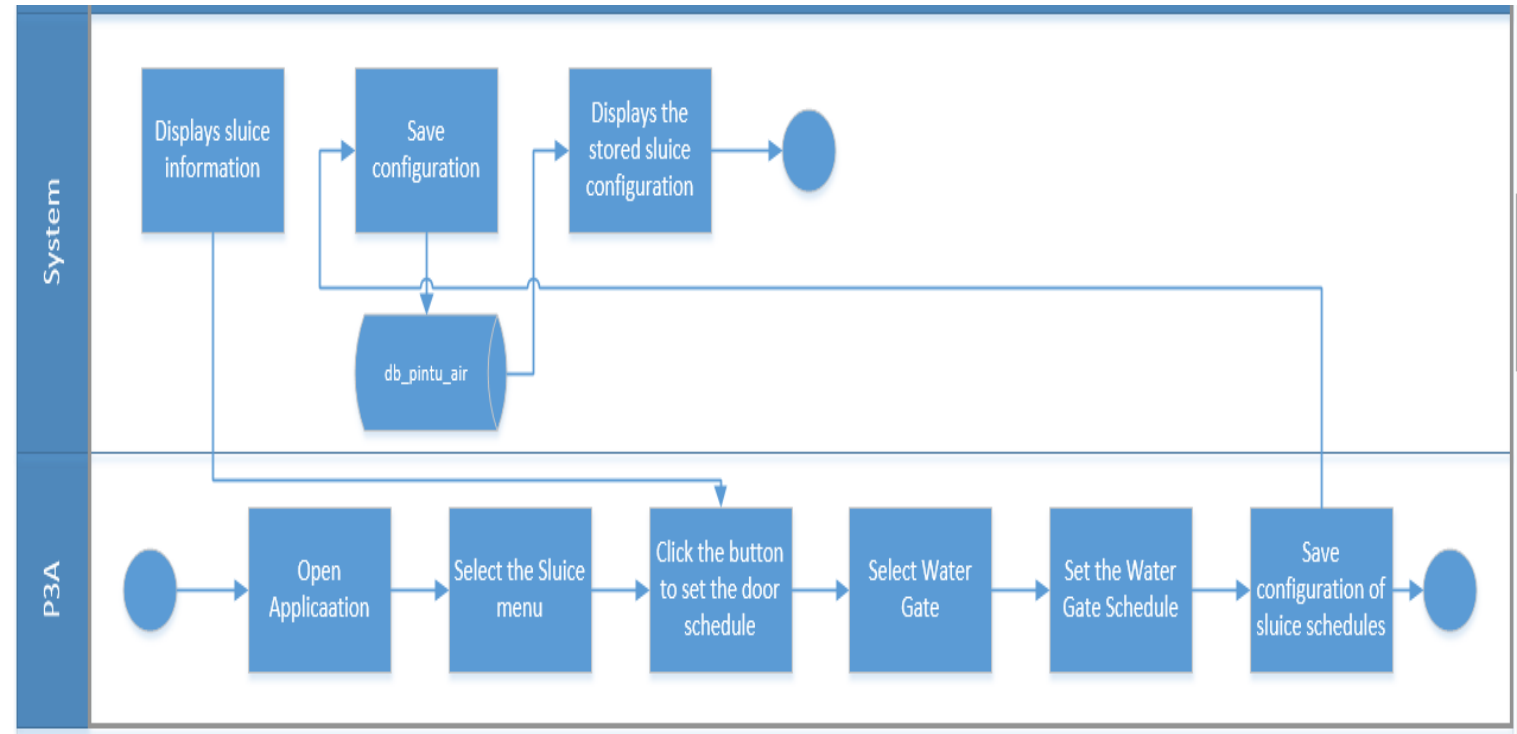

Figure 2. A business process model to set the schedule of the sluice

Figure 2 shows the flow of the business process from the control schedule of floodgates in the application that is developed in this research. Figure 3 shows the data analysis process related to monitoring the flow sensors and controls the business manual door. Figure 3 shows the business process from the application process data monitoring sensors and manual control of sluice that is developed in this research. P3A, as an irrigation Schedule Manager, involved as a user in the process of application development. As for the requirements, context-diagrams, data flow diagrams and can be seen in Table 1.

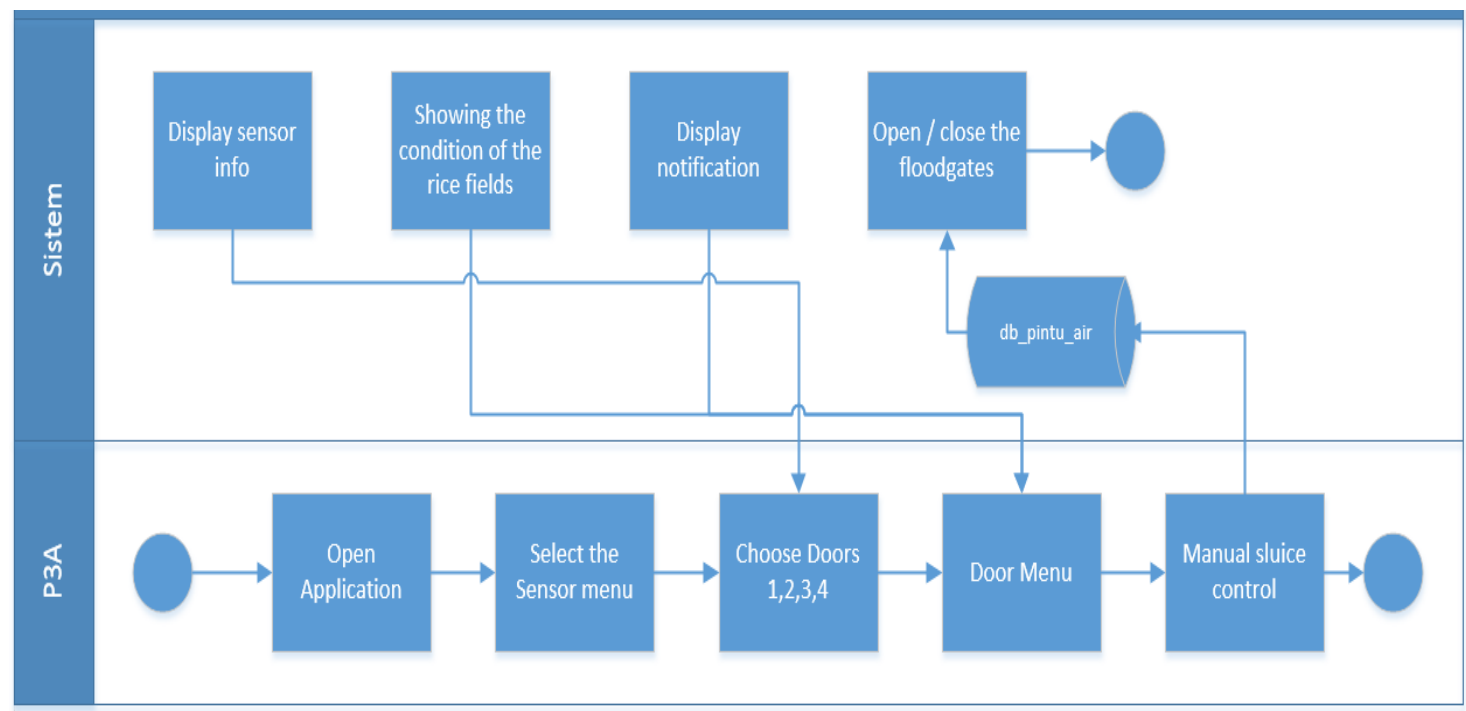

Figure 3. Model business process data monitoring sensors and manual control of sluice 
Table 1. User and system requirements

\begin{tabular}{ll}
\hline \multicolumn{1}{c}{ User Requirements } & \multicolumn{1}{c}{ System Requirements } \\
\hline P3A could control the schedule of the sluice operation. & $\begin{array}{l}\text { Water level information from each of the plot field } \\
\text { that already has sensors. }\end{array}$ \\
P3A could control the water manually outside of the determined schedule & $\begin{array}{l}\text { Sensor datainformation outputs } \\
\text { The opened sluice push notification outputs }\end{array}$ \\
P3A could see the water level information & $\begin{array}{l}\text { The rice field condition (normal or not) information } \\
\text { output }\end{array}$ \\
$\begin{array}{ll}\text { P3A could receive information through the notification of the sluice that opens } \\
\text { outside of the determined schedule }\end{array}$ & $\begin{array}{l}\text { Capable of controlling the sluice manually through } \\
\text { the application }\end{array}$ \\
\hline
\end{tabular}

\subsection{System design}

\subsubsection{Use case diagram}

Use case diagrams are used to model the system requirements and to declare the functions/services provided by the application to the user. Figure 4 displays the use case diagram. Figure 4 shows the two actors. The first actor, P3A, which can receive information via notifications of data sensors, control, schedule, control the sluice gate manually, and receive information about the condition of the field. The second actor, Arduino, which acts as an actor of the system hardware is located in the field, can send notifications and sensor data has been processed by an Arduino.

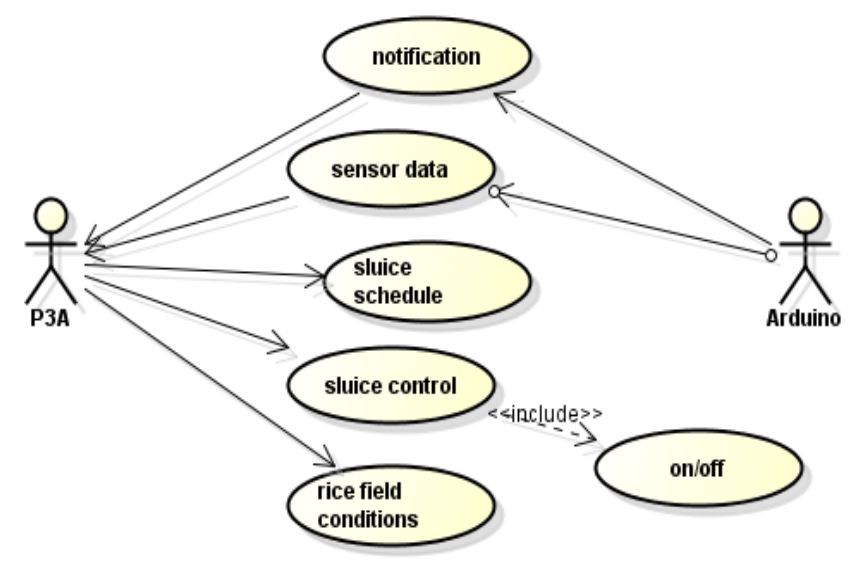

Figure 4. E-irrigation use case diagram

\subsubsection{Application design}

The initial design of the application can be seen in Figure 5 and Figure 6. Figure 5 shows some of the keys that will be used to move from one activity to another. Button 1 is used as a menu to control the schedule of the floodgates. Button 2 will be used for later moved to the activity menu sensor which can be seen in Figure 6. Users can view the information about the water height sensor and control the locks manually without having to wait for the irrigation schedule specified. This menu also accommodates some fragments to switch to other information regarding another sluice gate 1,2, 3, and 4 .

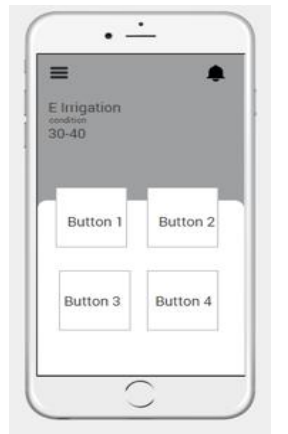

Figure 5. Dashboard

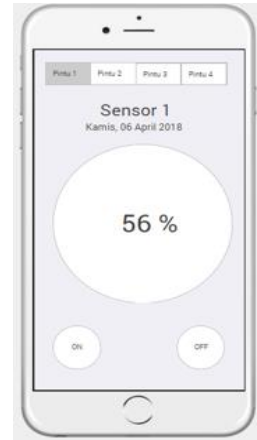

Figure 6. Monitoring sensor \& control 


\section{RESULTS}

\subsection{Implementation results/coding using android studio}

The development of implementation in this program was developed using the Android Studio based on a needs analysis has been designed. There are many features such as managing sluice schedules automatically, viewing altitude information and air gate controls, Water level information from each plot and users can also manually set sluice gates. These features also include fragment menus for gates 1, 2, 3, and 4. JSON data from backend services, originating from a MySQL database and use the postman, can be seen in Figure 7 and Figure 8. Figure 7 shows the sensor data in JSON format that is used in the application. The contents of the data are the result of the variable in the form of a data array containing data from ultrasonik_1 and ultrasonik_2. The application also shows the JSON data from each door water used as a signal. If it has a value of 1 then the gate is opened or closed and if the value is 0 , then the gateway does not perform any task.

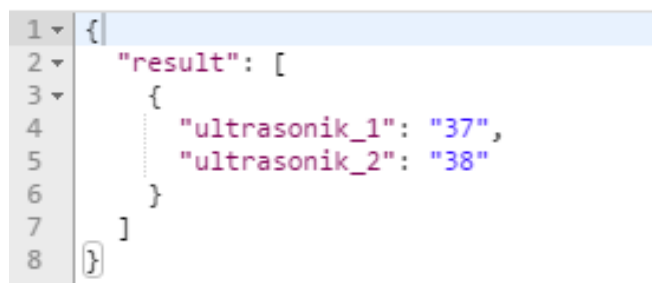

Figure 7. Data JSON sensor

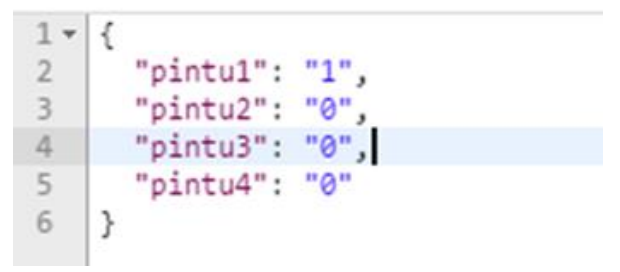

Figure 8. Data JSON sensor

\subsection{Usability testing}

Usability testing is used in this study using testing-post-study with a method of the System Usability Scale (SUS) [24]. SUS is an effective usability testing packages and reliable for use in various products and applications [25]. SUS is composed of 10 questions using a Likert scale of 1 to 5, the question posed to 15 respondents. Recapitulation table SUS can be seen in Table 2. Figure 9 shows SUS testing graph. Based on the results of the recap of the score data SUS respondents in Table 1, the average value of SUS was 76.5. From the results of the average value of SUS which has been retrieved, and they are matched based on the SUS Score is shown in Figure 10. Based on matching SUS Score, score SUS average belongs to the good because the standard SUS average is 68.0 with details of the 15 respondents: 0 respondents provide an assessment that the application cannot be accepted, 6 respondents rated marginal and 9 respondents stated that the application system is acceptable. While in Class, Rating Scale category application gets a grade of $\mathrm{C}$, and in ranking Adjective Rating the app is in the category of "good" because it has an average rating of SUS 76.5 .

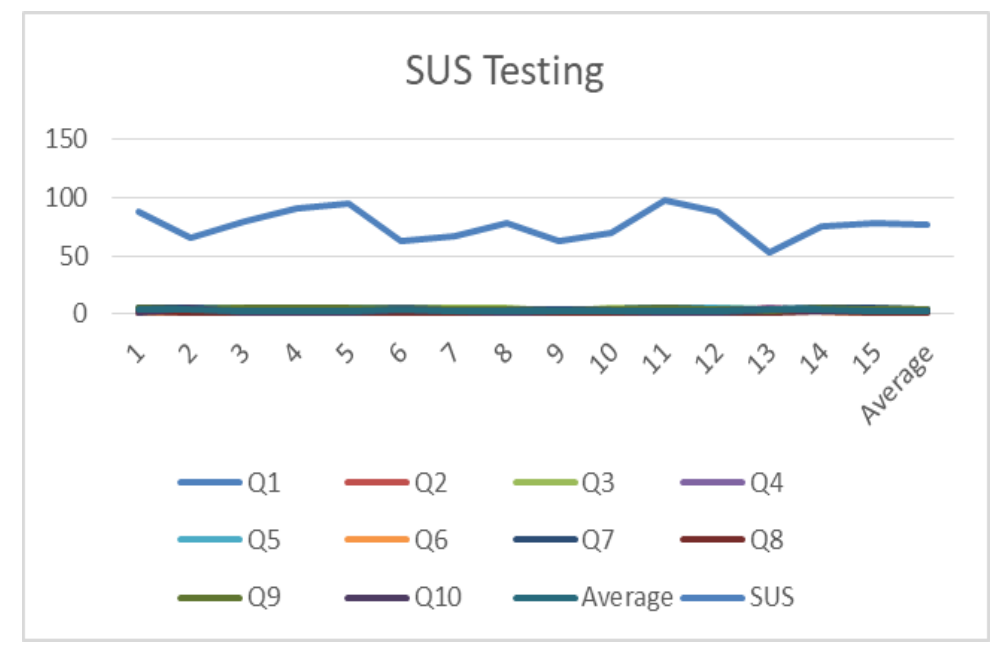

Figure 9. SUS testing graph 
Table 2. SUS recapitulation table

\begin{tabular}{ccccccccccccc}
\hline Respondent & Q1 & Q2 & Q3 & Q4 & Q5 & Q6 & Q7 & Q8 & Q9 & Q10 & Average & SUS \\
\hline 1 & 5 & 1 & 5 & 2 & 5 & 2 & 5 & 3 & 5 & 2 & 3,5 & 87,5 \\
2 & 4 & 3 & 5 & 4 & 5 & 3 & 5 & 2 & 4 & 5 & 4 & 65 \\
3 & 4 & 1 & 5 & 4 & 4 & 2 & 4 & 1 & 5 & 2 & 3,2 & 80 \\
4 & 4 & 2 & 5 & 1 & 4 & 2 & 5 & 1 & 5 & 1 & 3 & 90 \\
5 & 5 & 1 & 5 & 2 & 5 & 1 & 4 & 1 & 5 & 1 & 3 & 95 \\
6 & 2 & 4 & 5 & 3 & 4 & 2 & 5 & 2 & 4 & 4 & 3,5 & 62,5 \\
7 & 4 & 3 & 5 & 2 & 3 & 3 & 4 & 2 & 4 & 3 & 3,3 & 67,5 \\
8 & 3 & 1 & 5 & 2 & 4 & 2 & 4 & 2 & 4 & 2 & 2,9 & 77,5 \\
9 & 4 & 2 & 3 & 3 & 4 & 3 & 4 & 2 & 3 & 3 & 3,1 & 62,5 \\
10 & 4 & 2 & 5 & 3 & 4 & 3 & 4 & 2 & 4 & 3 & 3,4 & 70 \\
11 & 5 & 2 & 5 & 1 & 5 & 1 & 5 & 1 & 5 & 1 & 3,1 & 97,5 \\
12 & 4 & 1 & 5 & 2 & 5 & 2 & 4 & 1 & 4 & 1 & 2,9 & 87,5 \\
13 & 4 & 5 & 4 & 5 & 4 & 3 & 4 & 1 & 3 & 4 & 3,7 & 52,5 \\
14 & 5 & 3 & 5 & 3 & 5 & 3 & 5 & 3 & 5 & 3 & 4 & 75 \\
15 & 4 & 1 & 5 & 3 & 4 & 2 & 5 & 2 & 4 & 3 & 3,3 & 77,5 \\
Average & 4,06 & 2,13 & 4,8 & 2,67 & 4,33 & 2,26 & 4,47 & 1,73 & 4,26 & 2,53 & 3,32 & 76,5 \\
\hline
\end{tabular}

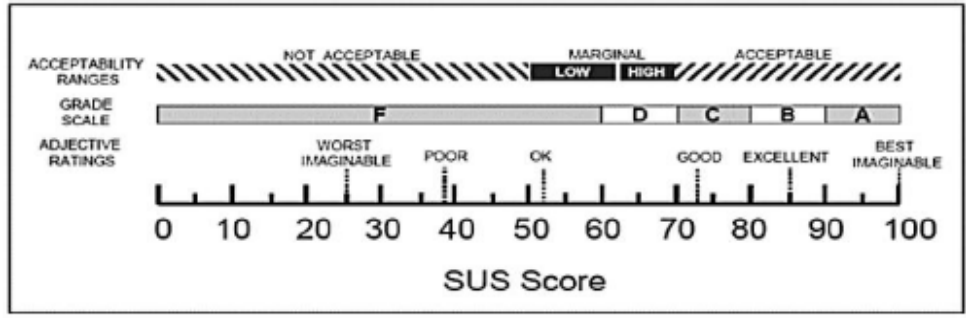

Figure 10. SUS score [25]

\section{CONCLUSION}

Based on the results of the discussion, it can be concluded that the mobile application has been developed using the method Waterfall. That used for automation of distribution and irrigation monitoring system based on integrated mobile application scheduling. In order to deserve to be used based on results of usability testing that produces a value of 76.5 (acceptable) due to the standard value of SUS was 68.0.

\section{FUTURE WORK}

Mobile application development for irrigation, monitoring, and distribution automation system based on integrated mobile application scheduling "E-irrigation" still needs to be improved in the security side. So that further development is expected to test on the security side and added security for mobile applications "E-irrigation".

\section{ACKNOWLEDGEMENTS}

This research was funded by the Directorate General of Higher Education, the Indonesian Ministry of Technology and Higher Education Research through the "Competitive Research Grant Scheme 2018" with Number Grant: PSNI-087/SKPP/III/2018.

\section{REFERENCES}

[1] Y. Setiawan, Liyantono, A. Fatikhunnada, P. A. Permatasari, and M. R. Aulia, "Dynamics pattern analysis of paddy fields in Indonesia for developing a near real-time monitoring system using modis satellite images," Procedia Environmental Sciences, vol. 33, pp. 108-116, 2016.

[2] A. A. Sulaiman, A. Candradijaya, and M. Syakir, "Technological Advancement and the Economic Benefit of Indonesian Rain-Fed Farming Development," Advances in Agriculture, vol. 2019, no. 9689037, pp. 1-8, May 2019.

[3] D. F. Yohannes, C. J. Ritsema, H. Solomon, J. Froebrich, and J. C. van Dam, "Irrigation water management: Farmers' practices, perceptions and adaptations at Gumselassa irrigation scheme, North Ethiopia," Agricultural Water Management, vol. 191, pp. 16-28, September 2017.

[4] F. Hadizadeh, M. S. Allahyari, C. A. Damalas, and M. R. Yazdani, "Integrated management of agricultural water resources among paddy farmers in northern Iran," Agricultural Water Management, vol. 200, pp. 19-26, March 2018. 
[5] S. Chandra, "Agriculture Irrigation System for Rice Crops using Neural Network (AIS)," International Journal of Engineering Technology, Management and Applied Sciences (IJETMAS), vol. 2, no. 4, pp. 79-83, September 2014.

[6] A. Pardossi et al., "Root Zone Sensors for Irrigation Management in Intensive," Sensors, vol. 9, no. 4, pp. 2809-2835, Apr. 2009.

[7] A. Yudhana and A. C. Kusuma, "Water quality monitoring at paddies farming based on android," IOP Conference Series: Materials Science and Engineering, vol. 403, no. 1, October 2018.

[8] Y. R. Wang and Z. W. Zheng, "Research of tomato economical irrigation schedule with drip irrigation under mulch in greenhouse," 2016 Fifth International Conference on Agro-Geoinformatics (Agro-Geoinformatics), Tianjin, pp. 1-5. 2016.

[9] Z. Jiayu, X. Shiwei, L. Zhemin, C. Wei and W. Dongjie, "Application of intelligence information fusion technology in agriculture monitoring and early-warning research," 2015 International Conference on Control, Automation and Robotics, Singapore, pp. 114-117, 2015.

[10] F. Kurniawan, H. Nurhayati, Y. M. Arif, S. Harini, S. M. S. Nugroho, and M. Hariadi, "Smart Monitoring Agriculture Based on Internet of Things," 2018 2nd East Indonesia Conference on Computer and Information Technology (EIConCIT), Makassar, Indonesia, pp. 363-366, 2018.

[11] A. Goap, D. Sharma, A. K. Shukla, and C. Rama Krishna, "An IoT based smart irrigation management system using Machine learning and open source technologies," Computers and Electronics in Agriculture, vol. 155, pp. 41-49, December 2018.

[12] N. K. Nawandar and V. R. Satpute, "IoT based low cost and intelligent module for smart irrigation system," Computers and Electronics in Agriculture, vol. 162, pp. 979-990, July 2019.

[13] H. F. Hawari, A. A. Zainal, and M. R. Ahmad, "Development of real time internet of things (IoT) based air quality monitoring system," Indonesian Journal of Electrical Engineering and Computer Science (IJEECS), vol. 13, no. 3, pp. 1039-1047, March 2019.

[14] S. Navulur, A. S. C. S. Sastry, and M. N. Giri Prasad, "Agricultural management through wireless sensors and internet of things," in International Journal of Electrical and Computer Engineering(IJECE), vol. 7, no. 6, pp. 3492-3499, December 2017.

[15] C. F. Liao and P. Y. Chen, "ROSA: Resource-Oriented service management schemes for web of things in a smart home," Sensors, vol. 17, no. 10, pp. 1-28, Sep. 2017.

[16] M. Khan, B. N. Silva, and K. Han, "A web of things-based emerging sensor network architecture for smart control systems," in Sensors, vol. 17, no. 2, Febuary 2017.

[17] P. Aswini, P. G. M. Rao, and P. Kollamudi, "Mobile Irrigation System," International Journal of Advanced Research (IJAR), vol. 4, no. 9, pp. 476-480, Sep. 2016.

[18] Singapore Management University, "Digital Media in Indonesia," pp. 2013, 2013.

[19] B. R. Nandkishor and A. Shinde, "Android Smartphone Based Body Area Network For," Int. J. Electr. Electron. Data Commun., vol. 2, no. 4, pp. 66-69, 2014.

[20] A. Nasiakou, M. Vavalis, and D. Zimeris, "Smart energy for smart irrigation," Computers and Electronics in Agriculture, vol. 129, pp. 74-83, November 2016.

[21] A. Mérida García, I. Fernández García, E. Camacho Poyato, P. Montesinos Barrios, and J. A. Rodríguez Díaz, "Coupling irrigation scheduling with solar energy production in a smart irrigation management system," Journal of Cleaner Production, vol. 175, pp. 670-682, Febuary 2018.

[22] Sunardi, S. A. Akbar, F. Noviyanto, E. Wibowo, and R. Naufal, "Irigation distribution automatization based on scheduling system," in IOP Conference Series: Materials Science and Engineering, vol. 403, pp. 1-6, 2018.

[23] R. Pressman and M. Bruce, "Software Engineering: A Practitioner's Approach," 8th ed. New York: McGraw-Hill Education, 2014

[24] J. Brooke, "SUS - A quick and dirty usability scale," Usability Eval. Ind. CRC Press, pp. 189-194, 1996.

[25] A. Bangor, T. Staff, P. Kortum, and J. Miller, "Determining What Individual SUS Scores Mean," Journal of usability Studies, vol. 4, no. 3, pp. 114-123, May 2009. 